\title{
Coastal tourism, climate change uncertainties and adaptation options
}

\author{
A. Magnan \\ Institute for Sustainable Development and International Relations \\ (IDDRI) Sciences Po, France
}

\begin{abstract}
This text aims to show that in addition to the uncertainties concerning the impacts of climate change, another major source of uncertainty must also be considered: that which arises from the evolution of tourist requirements and their attitudes towards coastal practices. Nevertheless, we argue that these uncertainties cannot be an excuse to wait for more precise scientific knowledge to emerge and that a number of principles for adaptation can be highlighted.
\end{abstract}

Keywords: coastal tourism, climate and anthropogenic uncertainties, adaptation, Mediterranean.

\section{Introduction}

Coastal tourism is a crucial issue for numerous countries all over the world due to its economic weight on local, national and regional economies. In the Mediterranean, for example, and since the beginning of this decade, annual growth of the industry has ranged between 3 and $4 \%$. Every year the basin is visited by more than 300 million tourists, a number which is expected to increase to 400 million in 2025 [1]. These figures encompass international as well as domestic visitor flows. Overall, the beach holiday formula plays a key role, as it remains a defining characteristic of $80 \%$ of Mediterranean tourism activity [2]. This example highlights that current tourism behaviours are significantly influenced by the "Sea, Sand and Sun" fashion trend which partly relies on the climatic and environmental features of destinations. However, climatic factors are not the sole drivers of tourists' choices [3], although they are important [4]. Consequently, two main dynamics must be considered when trying to imagine 
the future of tourism: the impacts of climate change and the evolution of the societal expectations regarding tourism at the world and national scales.

Several works have already highlighted the fact that as climate change occurs, there will be both losers and winners in terms of destination attractiveness [5-8]. Therefore, we can expect a reorganisation of tourism flows at the scale of the world in addition to a smaller one. It is currently impossible to say with confidence which areas will benefit from the changing climatic conditions, and which ones will be seriously affected. It means that we still unable to predict precisely the spatial and temporal redistributions of future tourism flow. This difficulty stems from two main sources of uncertainty: the first concerns climate change impacts at a local scale; the second relates to the evolution of international and domestic tourist desires and practices over the coming decades. Nonetheless, it is crucial for the stakeholders involved, from international companies to the local authorities at a destination, to have a comprehensive view of what they can do in terms of building realistic scenarios.

One option is to wait for the emergence of more precise scientific knowledge on climate impacts and how they might affect tourist behaviour, prior to the instigation of strategies and development plans. However, this choice is clearly unsatisfactory, firstly because it has now been established that some of the effects of climate change are irreversible, and secondly because there is no evidence to suggest that climatic and anthropogenic uncertainties will be reduced over the next decades.

Without neglecting the necessity to improve scientific knowledge on the impacts of climate change at a local scale (through climate modelling and environmental and economic research) nor disregarding potential changes in tourist behaviour (social sciences), the hypothesis this text supports is that some options exist which are relevant for adaptation to climate change. Indeed, their objective main objective is not to address future perturbations directly, but to provide territorial systems with a degree of flexibility to enable both known and unknown situations to be addressed. This approach reflects our conviction that flexibility is one of the main pillars of adaptation to climate change [9-12].

The text is organized in four main parts. The first (section 2) provides a brief overview of the complex relationship between climate change and tourism. The second (section 3) focuses on the induced limitations and then on the existence of strong difficulties to forecast climate and anthropogenic changes over the coming decades. Yet, these barriers cannot be used as an excuse to do nothing (section 4) because some options currently exist to by-pass them. The last part (section 5) presents five of these adaptation principles on which destinations' development should be based.

\section{The complex links between tourism and climate change}

This part of the paper will be brief as numerous scientific publications have already studied the relationship between tourism and climate $[2,4,13,14]$. A short synthesis is presented, highlighting some key elements to take into account for further discussion. 


\subsection{The role of climate in the tourism rationale}

To focus on the complex relationship between coastal tourism and climate change (expected trends and associated risks) requires a preliminary look at the relative importance of climatic factors in tourism itself. Indeed, "tourism requires and uses a geographical space [... which] has a physical substrate (...) consisting of physical and biological elements (...); and also elements created by human activity" [15: 572]. This signifies that environmental conditions, and particularly climatic ones, are not the sole factors that influence whether or not a territory becomes a tourist destination. Another important feature is the accessibility of the destination, i.e. the overriding factor for the Mediterranean is how reachable it is to the rest of Europe. The quality of air connections, travel costs, accessibility of accommodation from the airport e.g. are some of the important determinants of destination choice, which exist in addition to the influence of weather $[16,17]$. Another kind of endogenous determinant is the political stability of a country. In parallel, exogenous factors play an equally important role in shaping the choices made by tourists; these include the socioeconomic situation in a tourist's country of origin and, more generally, psychological trends (e.g. behaviour patterns). This means that tourism responds neither to a type of natural and climatic determinism nor to a simple economic, social or cultural determinism. Tourist choices result from a subtle combination of highly diverse factors, the respective importance of which often varies from one society to another and according to the time of year.

This does not mean that climatic factors can be neglected, but that they must be considered as "background conditions". Therefore, from a strictly climatic viewpoint, five variables are typically recognized as having a definite influence on tourism $[7,8,18]$ : temperature, sunshine, rainfall, wind and humidity. These variables are generally considered in relation to the destination because it is here that they are assumed to dictate attractiveness to tourists. Some authors, however, emphasize the necessity to also consider the places where tourists depart from $[6,13,19,21]$ because, if we examine the situation more closely, the real determining factor, once again from a climatic perspective, is the contrast between the daily living conditions of the tourists and those of the place they go for a limited time. This positioning appears particularly relevant when looking closely at the probable consequences of climate change on tourist flows at different scales.

\subsection{The impacts of climate change on the tourism activity}

Another argument, which encourages the consideration of climate components among other factors and without any a priori hierarchy, focuses on the manner in which climate change will impact the tourism activity. This influence will not only include direct effects (e.g. changes in temperatures, precipitations and winds) but also, and perhaps mainly, indirect consequences. Such effects may arise from climatic changes that result in modifications to the environment and natural hazards (e.g. increase or decrease in the frequency and intensity of storms, flooding and droughts). These environmental impacts may subsequently 
affect resources such as land or water, which in turn will influence human activities through changes in economic and social processes.

The impacts on the tourism sector have been classified into four main categories by Scott et al. [22]. (i) Direct impacts include increased climate variability, modification to the occurrence of extreme events, health and safety repercussions, and others. Then, it will add a level of complexity to the tourism industry current management rationales. Nevertheless, local 'improvements' are also possible such as, for example, the extension of the favourable climatic conditions period. (ii) Indirect impacts encompass environmental changes such as a reduction of the availability of natural resources (e.g. water), a loss of land area due to coastal erosion and flooding, and changes in marine ecosystems (e.g. presence of jellyfish, decrease in biodiversity and/or diving visibility). Conflicts are likely to increase/arise between local communities and the tourism sector because the pressure exerted by climate change on attractive but resource limited ecosystems represents a major threat to the related activities (e.g. diving vs. fishing, golf $v s$. agriculture). (iii) Greenhouse gases (GHG) emissions mitigation policies will also have indirect impacts on tourism, for example through transportation costs and energy savings. These impacts could prove to be as decisive for tourism as those of climate change itself. Finally, (iv) climate change is expected to have very indirect consequences on society, in particular on lifestyles, economic growth, political stability, etc.

When combined, these four types of impacts will affect the vulnerability of specific destinations and tourism sectors, and more generally the competitiveness of destinations. It will very likely lead to the seasonal and spatial redistributions of tourism flows. For example in summer, the mass movement from northern Europe towards the Mediterranean could break down as northern Europeans find that tourist destinations closer to home are increasingly satisfying; while Mediterranean populations may be more likely to seek milder climes in the north. Conversely, in autumn and winter the north-south flow could intensify. While there is no reason to believe that climate change will induce a decrease in the total number of visitors, quantifying and qualifying future trends proves difficult, particularly because international tourism will not react to climate evolutions in the same manner as domestic tourism.

This point underlines the high level of interconnectivity between the relevant factors, and that the main challenge imposed by climate change is the need to consider tourism territories as complex systems. This is not in itself a new challenge, but what we argue is that the reality of climate change and of its associated threats provides a concrete opportunity for the implementation of such a global and systemic vision. Sustainability of tourism, and indirectly of destinations' economies, depends on this ability to be pragmatic. And it is at this stage that the problem emerges concerning the uncertainty over the impacts and future reactions of societies. 


\section{Uncertainties}

\subsection{Environmental uncertainties}

"(...) Any consideration of the effects of greenhouse warming on tourism is highly speculative" [6: 176]. This statement remains true today and is related to the difficulty involved in refining climate modelling. The problem stems from limitations that arise from four main sources [23]. The first (i) concerns the lack of knowledge on the future trajectories of GHG emissions, which are themselves determined by socioeconomic evolutions. The second source (ii) is strictly linked to the functioning of models. This uncertainty is inherent to a model's structure (the type of equations) and to the differences between parameterisation from one model to another. A third source (iii) relies on the long-term unpredictability of natural climate variability (droughts, floods, storms, El Nino Southern Oscillation, North Atlantic Oscillation, etc.). Finally, a fourth source of limitation (iv) refers to the difficulty involved with integrating exhaustive physical and environmental local features and their interactions (salinity of marine waters, type of terrestrial vegetation, nature of hydrographical network and soils...) into climate models.

Together these four limitations explain why climate projection is a highly uncertain exercise. Sources (i) and (iii), in particular, encourage the belief that climatic uncertainties will not be reduced over the next decades. These constraints also account for the IPCC's use of six GHG emission scenarios rather than just one; and explain why current projections offer a range of possible outcomes instead of reaching only one number. For example, concerning sea level rise, the global models used by the IPCC concur on an elevation range at the world scale and for all SRES scenarios between $18 \mathrm{~cm}$ and $59 \mathrm{~cm}$ by 2100 . Formerly, this range was typically summarized by using the mean of $38 \mathrm{~cm}$; however a rise of $38 \mathrm{~cm}$ is no more likely than a rise of $18 \mathrm{~cm}$ or $59 \mathrm{~cm}$. Similarly, the six SRES scenarios reflect neither the most probable nor the entire range of possible GHG emission trajectories. The margins of uncertainty remain extremely high, particularly when considering the rate of ice melt utilized by the equations of models. Thus, some hypotheses indicate a sea level elevation at the global scale of more than one metre during the current century, and up to tens of metres over longer time scales $[24,25]$. Consequently, climate change implications for coastal tourism and physical impacts at local scales are themselves for the moment partially unpredictable.

The issue becomes increasingly complicated when the uncertain responses of ecosystems to climate evolutions are also taken into account. For example, some authors have highlighted the role of coralline ecosystems, arguing scientific knowledge is currently insufficient to forecast the behaviour of coral reefs in response to future sea level rise along particular stretches of coastline [26]. Three types of reactions can be expected according to the capacity of coral reefs to grow at the same rate as the level of the sea. This ability depends on a combination of factors including the species of coral, the reef type, marine currents, the degree to which human development disturbs environmental 
processes, etc. The same circumstances exist when considering the extension of posidonia in the Mediterranean. For these reasons coral reefs and posidonia can be considered as providers of natural protection (buffer zones) for coastlines against swells. They play a significant role in the moderation of marine erosion. The main conclusion here is that due to a lack of knowledge on the way in which all of the components of coastal ecosystems will respond to climate change, it is not possible to identify with certainty the reaction of the system itself. This implies for example that the unequivocal relationship commonly assumed to exist between climate change and coastal erosion must be viewed with caution. Furthermore, and because the impacts will potentially vary widely from one place to another, forecasts are needed to be contextualized.

\subsection{Anthropogenic uncertainties}

What will be the future of Mediterranean tourism? Will beaches continue to be attractive? Here, we argue that it is structurally impossible to obtain precise answers to these questions and that anthropogenic uncertainties are, and will be, at least as limiting as climate ones. Schematically, three main sources of anthropogenic uncertainties must be considered which restrict forecasts of the evolution of (i) the accessibility of destinations, (ii) their market opportunities and (iii) their general attractiveness.

(i) The first source of anthropogenic uncertainty on tourism evolution is related to the impacts of mitigation policies [2, 27]. Reducing GHG emissions will indeed be increasingly determined by policy choices, which will affect the tourism industry through restrictions on transportation, accommodation and activities. As it constitutes the greatest GHG emission source from the tourism sector, air transportation will be seriously affected. This will inevitably lead to a modification of the accessibility of local destinations, mainly because GHG emission restrictions are likely to result in an increase in airfares. But how will tourists react to an increase in the cost of air travel? Will they no longer travel as far? Will they choose closer destinations? Will they continue to travel far but stay longer in the same destination? While numerous hypotheses exist at present, the only thing we can say for certain is that there will be a difference between "popular" and luxury markets. Indeed, it is not difficult to suppose that while an increase in airfares may not drastically reduce the ability of rich people to travel, it will seriously the one capacity of less affluent tourists to do so. Consequently, "popular" destinations will probably be more affected by mitigation policies in transportation than more luxurious ones. This is bad news for the Mediterranean which has acquired a reputation for providing inexpensive access to sun and sea. At the same time, restrictions on air facilities will indirectly have impacts on domestic tourism flows (increase?). Taking these conclusions into account, the difficulty in forecasting the evolution of tourism flows remains clear.

(ii) Forecasting future market opportunities is complicated by the fact that climate change will not be the sole driver of changes in the Mediterranean [1, 20, 28]. Socioeconomic trends will also influence the ability of populations to develop domestic as well as international tourism activities. Non climatic drivers refer to the evolution of the social and economic inequalities at the national and 
regional scales. However, we must keep in mind that even if these changes follow their own logic, climate change will affect the general conditions.

(iii) The evolution of tourist choice will also depend on societal changes, such as variation of the population pyramid, the emergence of an environmental conscience, the evolution of international and geopolitical relationships, etc. Finally, there is a real difficulty envisaging the effects of climatic as well as anthropogenic changes on tourist behaviour and indirectly on the current attractiveness of tourism destinations. In a global perspective, there is no evidence to confirm that coastal leisure will be as popular in 2050 as it is today. We must remember that at the end of the $18^{\text {th }}$ century and until the end of the Second World War, people went to the Mediterranean coasts in winter, mainly for health reasons. Fashions in tourism certainly change over time, as does the criteria of the attractiveness of places to individuals and communities. The problem is that we are unable to say in which way these factors will change in future.

\section{One certainty often omitted: adaptation is not an option}

Paradoxically, one strong certainty is often omitted: climate change is underway and its effects within the coming half-century are at least partly unavoidable because of atmospheric latency phenomena. The irreversibility of the trend has been demonstrated at shorter as well at longer time scales, from decades to millennia [29, 30]. We will therefore have to manage what is already inevitable.

Confronting the irreversibility of climate change and its potential impacts on coastal tourism requires deliberation on the question of what must be done today. One could argue that the main need is to define anticipative strategies to prevent disruptions. However, because of the uncertainties associated with the physical impacts, it is important to understand that reactive strategies are also necessary. Thus, the authorities responsible for the management of tourism destinations must identify a suitable compromise between the ability to anticipate and the capacity to react. It is in our view that this compromise is dependant from the ability of the tourism territory to adjust its development choices as changes occur. This is why we argue that building and strengthening this compromise is one of the main mechanisms for adapting to climate change. Indeed, the concept of adjustment highlighted by the IPCC in its definition of adaptation to climate change refers to the idea of flexibility; yet, flexibility allows a system to change its structures, modes of operation and its development strategies according to disturbances that occur. Adaptation thus appears to be both a picture of the system at a given time (is it suitable or not?) and a continuous and dynamic process by which this system adapts. A form of adaptation at a given moment and in a specific context is therefore likely to change over time. This demonstrates that favouring flexibility mechanisms constitutes a relevant solution to the problem of dealing with uncertainties. 


\section{Adaptation options to encounter uncertainties}

Different measures can already be implemented on the basis of certain fundamental principles that are relevant for a tourism territory because they are relatively independent from the gaps in scientific knowledge (uncertainties). Then, they can prove useful to tackle the barriers usually associated with climate change, mainly because by helping a destination to build resilient and anticipative strategies, they improve its ability to be flexible. Five principles are described below.

Accepting uncertainty(ies) - One of the most important aspects of adaptation is to anticipate the coming changes. To anticipate means firstly to be able (i) to modify tourism processes. We can indeed simultaneously influence fashion trends in beach tourism and travel modes (e.g. by encouraging transport by train instead of aeroplane for short distances). However, all future changes, such as sea level rise e.g., will not be controllable by human ambitions alone. Therefore to anticipate also means (ii) to implement strategies likely to reduce the impacts of climate change. Anticipation is then as much fighting to reduce the exposure to risks as it is to limit their consequences. At this stage, uncertainties create barriers and the question arises whether they constitute a real problem or not. Uncertainty over the future has indeed been a constant factor in the development of human societies, but for the last two centuries we have become accustomed to act on the basis of judged reliable scientific knowledge. The challenge of climate change thus questions modern development models. To what extent does the absence of knowledge limit the implementation of sustainable development? In parallel and as previously said, adaptation is clearly one of the keys to overcome uncertainty because, as it is a process, it allows adjustments to be made to development choices as events and evolutions occur. To refuse to accept the existence of uncertainty can lead to misjudgements that may potentially reinforce the initial effects of climate change. However, to accept uncertainty assumes a progression in the attitudes and behaviours of all components of society (local populations, tourists, decision-makers, managers).

Diversifying the local economy - An economic structure that is based upon several different pillars has potentially a greater adaptive capacity than a less diversified economy, such as one that focuses solely on the tourist industry. The risks are numerous because if tourism is endangered, from a one off incident or gradually over time, the functioning of the entire destination will be threatened due to the loss of revenues and jobs, i.e., and because there would be no rapid compensation from other economic sectors. An overly specialized economy limits the spectrum of jobs, competences and sources of revenue, and tends to limit the range of opportunities in terms of hazard response, innovation and anticipation. Conversely, destinations must also contemplate the thresholds to economic diversification as too many dissipated activities induce scattering effects, which again weaken the ability to respond to a major disruption. These thresholds depend crucially on local contexts, namely on the specificities of a destination (natural resources, social and economic capacities, spatial configuration, cultural values, etc.) and on national structures (institutions, rules, 
general level of development, etc.). The Mediterranean certainly offers a great diversity of situations and the economic diversification of local tourism territories should not be standardized throughout. Nevertheless, the competitive context at the regional level must be taken into account. The importance of promoting local specificities constitutes, from our viewpoint, one of the priorities for destinations to enable the development of an adaptive capacity for tourism.

Diversification of clientele - International and domestic tourists must be distinguished as two different sources of tourism revenue. These two main categories are characterized by several fundamental differences, which include: tourist motivations (means, tastes, expectations and practices); distinct networks of stakeholders involved with either group; financial capacities; sensitivity to disruption (climate-related, but also political and health-related, etc.); modes of travel; and trip duration. The respective vulnerabilities of each tourist sector are thus likely to be contrasting. The underlying idea here is that the international tourism sector presents a more developed adaptive capacity than domestic tourism; however this does not mean that destinations should privilege the former in tourism development strategies. Indeed, except when an individual has a real interest in the cultural attractions of a particular destination (to visit the Egyptian pyramids or the Greek Acropolis for example), the international beach tourist is volatile in the sense that his attachment to a specific Mediterranean coast can ultimately be limited. Such a tourist can therefore appear rather mobile in his choice of destination because, as we have seen, climatic factors are not the only ones involved. The picture is much more complicated for a domestic tourist originating from a developing country. This tourist has more limited access to remote destinations and for him, the coast of his own country - that he can reach by road or rail - is more attractive than it would be to a foreign tourist. In fact the domestic tourism market segment has an advantage over the international segment, in that it offers more guarantees of stability in terms of international competition, even if unfavourable climate change occurs. One adaptation option therefore consists of the reinforcement of domestic attractiveness by differentiated tariff systems, diversification of tourism products, etc.

Building contextualized destination images - The line of reasoning above encourages a rethinking and/or creation of local tourism services to take into account a broad range of factors, and not just those related to the climate. The specifics of local identity, for example, can be put forward to counterbalance the potential loss of climate attractiveness. The main purpose of constructing an image of a destination that is less dependent on climate conditions is that, contrary to the limited "Sea, Sand and Sun" formula, the cultural characteristics of a region (customs, beliefs, lifestyles, etc.) are less variable and, at the very least, are not directly threatened by climate change. These points can therefore be regarded as central elements for the promotion of more stable tourism, in preference to a continual reliance on the presence of beaches or the sea temperature. Furthermore, the diversification of tourism products allows local destinations to mainstream climate change challenges into general development issues. Once again, the threat of climate change can be said to provide a 
pragmatic opportunity for the implementation of what is known as 'integrated' or 'sustainable' tourism, which at the moment remains a vague concept.

Considering the changes both in the origin and destination countriesChanges in tourist behaviour, together with natural developments, represent a major field of uncertainty. However, most existing analyses contain an inherent bias, which is that they consider the possible impacts of climate change in a unilateral manner, only focusing on what is likely to happen in specific destinations. Schematically, in the south of the Mediterranean: "temperatures will become too high and rain will drastically diminish, and therefore such coastal areas will lose their attractiveness and will be progressively abandoned by tourism; the tourists themselves will go somewhere else, whether in the Mediterranean basin or not". The bias in this analysis is that on one hand, tourist desires are assumed to remain the same as they are today, and on the other we neglect to consider the climate changes in the countries where tourists come from. Several studies have shown that poor climate conditions in Germany or England translate into more summer departures towards sunny destinations, although the opposite is also true. This clearly demonstrates that the determining issue influencing tourism flows, from a climatic point of view, is that they do not only depend on the conditions that a destination offers, but also on the climate differential between the tourist-producing and the destination countries. It therefore appears important, and even incontrovertible, that studies on the effects of climate change on the Mediterranean tourism flows, should be based on the climate change differences, and not only on the climate changes themselves.

\section{Conclusion}

Regarding tourism, this article has highlighted the two main sources of uncertainty that must be considered: climatic (impacts of climate change at local scales) and anthropogenic (evolution of tourists' desires). We have seen that even though uncertainties represent a serious constraint to the definition of adequate development options, a set of principles exist which can be beneficial for the adaptation of coastal touristic areas to climate change. Five of these principles were introduced and discussed in this paper, with reference to their value, as well as their limitations.

An interesting further question would be to look at the "assemblage" of these adaptation principles at the more concrete scale of local territories and their tourism sites. At this geographic level of analysis, all of the five general principles are not always equally relevant. Some of them must take precedence, even if numerous questions remain unanswered: which ones should be prioritized, what areas of a territory are most in need, what are the timescales of implementation? Etc.

\section{Acknowledgements}

The author acknowledges the European Commission (DG Research - CIRCE project - Climate change and impact research: the Mediterranean environment) as well as the Région Ile de France (R2DS project) for supporting his research. 


\section{References}

[1] Benoit, G. and Comeau, A., A sustainable future for the Mediterranean: the Blue Plan's environment and development outlook. Earthscan: London, 2005.

[2] Billé, R., Kieken, H. and Magnan, A., Tourism and climate change: challenges and prospects. MAP Technical Reports Series, 173, pp. 581$618,2009$.

[3] Gössling, S. and Hall, M.C., Uncertainties in predicting tourist flows under scenarios of climate change. Climatic change, 79, pp. 163-173, 2006.

[4] Besancenot, J.-P., Climat et Tourisme. Masson: Paris, 1990.

[5] Mieczkowski, Z., The tourism climatic index: a method of evaluating world climates for tourism. The Canadian geographer, 29, pp. 220-233, 1985.

[6] Smith, K., Tourism and climate change. Land use policy, 2, pp. 176-180, 1990.

[7] Lise, W. and Tol, R., Sensitivity of tourist destination choice to climate. In Giupponi, C., and Schechter, M., Climate change in the Mediterranean: socio-economic perspectives of impacts, vulnerability and adaptation. Edward Elgar Publishing: Cheltenham, pp. 290-318, 2003.

[8] Amelung, B. and Viner, D., Mediterranean tourism: exploring the future with the tourism climatic index. Journal of Sust. Tourism, 14, pp. 349-366, 2006.

[9] Burton, I., Vulnerability and adaptive responses in the context of climate and climate change. Climatic Change, 36, pp. 185-196, 1997.

[10] Smit, B., and Pilifosova, O., From adaptation to adaptive capacity and vulnerability reduction, In Smith J.B., R.J.T. Klein and S. Huq (Eds.), Climate change, adaptive capacity and development, Imperial College Press, pp. 9-28., 2003.

[11] IPCC, Climate Change 2007: Impacts, Adaptation and Vulnerability. Contribution of Working Group II to the Fourth Assessment Report of the Intergovernmental Panel on Climate Change, M.L. Parry, O.F. Canziani, J.P. Palutikof, P.J. van der Linden and C.E. Hanson; Eds., Cambridge University Press: Cambridge, UK, 2007.

[12] Magnan, A., Proposition d'une trame de recherche pour appréhender la capacité d'adaptation au changement climatique. VertigO, 9, [On line, URL : http://vertigo.revues.org/9189], 2009.

[13] Hamilton, J.M., Climate and the destination choice of German tourists. DINAS-COAST working paper, 2 (revised), 2003.

[14] Hamilton, J.M., Maddison, D.J. and Tol, R.S.J., Climate change and international tourism: a simulation study. Global Environmental Change, 15, pp. 253-266, 2005.

[15] Gómez Martín, B., Weather, climate and tourism: a geographical perspective. Annals of Tourism Research, 32, pp. 571-591, 2004.

[16] Céron, J.-P. and Dubois, G., The potential impacts of climate change on French tourism. Current issues in Tourism, 8, pp. 125-139, 2004. 
[17] UNWTO (World tourism organisation). Climate change and tourism: responding to global changes. Madrid, 2008.

[18] De Freitas, C.R., Scott, D. and McBoyle, G., A second generation climate index for tourism (CIT): specification and verification. International Journal of Biometeorology, 52, pp. 399-407, 2008.

[19] Mather, S., Viner, D. and Todd, G., Climate and policy changes: their implications for international tourism flows. In Hall, C.M. and Higham, J. (Eds.) Tourism, Recreation and climate change, Channel view publications, pp. 63-85, 2005.

[20] Perry, A., Impacts of climate change on tourism in the Mediterranean: adaptive responses. In Giupponi, C., and Schechter, M., Climate change in the Mediterranean: socio-economic perspectives of impacts, vulnerability and adaptation. Edward Elgar Publishing: Cheltenham, pp. 279-289, 2003.

[21] Bigano, A., Hamilton, J.M. and Tol, R., Climate change and tourism in the Mediterranean. FNU working paper, 157, 2008.

[22] Scott, D., Amelung, B., Becken, S., Ceron, J.-P., Dubois, G., Gossling, S., Peeters, P. and Simpson, M.C., Climate Change and Tourism: Responding to Global Challenges. UWTO-UNEP-WMO, synthesis report, 2007.

[23] Terray, L. and Braconnot, P., Escrime white paper: studies of climate change. IPSL-Météo-France: Paris, 2008.

[24] Hansen, J., Scientific reticence and sea level rise. Environmental Research Letter, 2, 6 p. (doi:10.1088/1748-9326/2/2/024002), 2007.

[25] Rahmstorf, S., Cazenave, A, Church, J.A., Hansen, J.E., Keeling, R.F., Parker, D.E. and Somerville, R.C.J., Recent Climate Observations Compared to Projections", Science (doi: 10.1126/science.1136843), 2007.

[26] Duvat, V., Peut-on prévoir les effets du changement climatique sur les littoraux coralliens? Proceedings of 12th International Symposium of the French Commission of Tropical Geography (Bordeaux, 16-18 Oct. 2008). to be published.

[27] Simpson, M.C., Gössling, S., Scott, D., Hall, C.M. and Gladin, E., Climate Change Adaptation and Mitigation in the Tourism Sector: Frameworks, Tools and Practices. UNEP, Oxford University: Paris, 2008.

[28] Magnan, A., Garnaud, B., Billé, R., Gemenne, F. and Hallegatte, S., The future of the Mediterranean: from impacts of climate change to adaptation issues, Iddri series (www.iddri.org): Paris, 2009.

[29] Parry, M., Palutikof, J., Hanson, C. and Lowe, J., Squaring up to reality. Nature, published online: 29 May 2008 (www.nature.com), 2008.

[30] Solomon, S., Plattner, G.-K., Knutti, R. and Friedlingstein, P., Irreversible climate change due to carbon dioxide emissions. Proceedings of the National Academy of Sciences (USA), 106, pp. 1704-1709, 2009. 